This document was prepared in conjunction with work accomplished under Contract No. DE-AC09-96SR18500 with the U.S. Department of Energy.

This work was prepared under an agreement with and funded by the U.S. Government. Neither the U. S. Government or its employees, nor any of its contractors, subcontractors or their employees, makes any express or implied: 1 . warranty or assumes any legal liability for the accuracy, completeness, or for the use or results of such use of any information, product, or process disclosed; or 2 . representation that such use or results of such use would not infringe privately owned rights; or 3 . endorsement or recommendation of any specifically identified commercial product, process, or service. Any views and opinions of authors expressed in this work do not necessarily state or reflect those of the United States Government, or its contractors, or subcontractors. 
WSRC-TR-2006-00363

\section{Studies to Support Deployment of Edible Oils as the Final cVOC Remediation in T-Area}

\section{Summary Report}

Brian Riha

Brian Looney

Miles Denham

Kitt Bagwell

Richard Hall

Carol Eddy-Dilek

Washington Savannah River Company, LLC

Savannah River Site

Aiken, SC, 29808

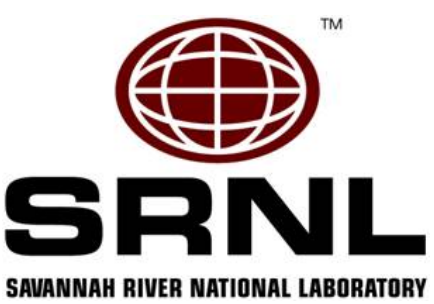

Prepared for the US Department of Energy under Contract DE-AC09-96SR18500 


\section{Contents}

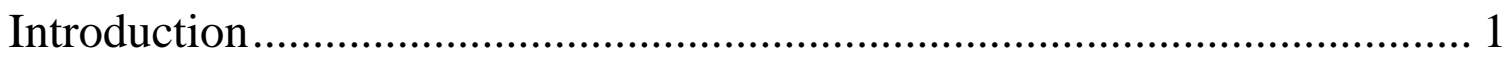

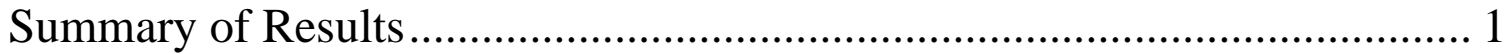

T-Area Background and Groundwater Conditions........................................ 2

Review of Edible Oil Remediation Processes .............................................. 6

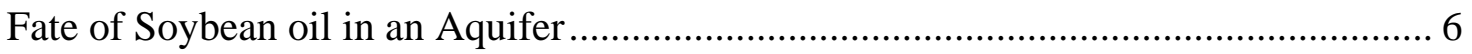

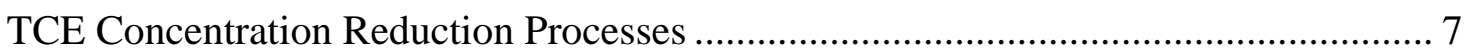

TCE Partitioning/Sequestration .............................................................................. 7

TCE Destruction - Anaerobic Reductive Dechlorination ............................................. 8

TCE Destruction - Cometabolism........................................................................... 8

Sequestration and Biodegradation Synergy …………............................................ 9

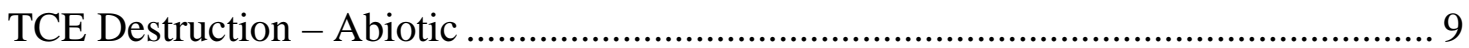

Review of the Theory and State of the Practice for Edible Oil Delivery ........................ 9

Studies to Specifically Support Edible Oil Deployment at T-Area.............. 11

Column Studies to Support NAPL Oil Deployment on the Water Table....................... 11

Geochemical Effects on Edible Oil Deployment for T-Area Groundwater .................. 11

Microbial Communities and Microcosm Studies for T-Area Groundwater .................. 12

Soybean Oil Deployment Results for Surrogate SRS Site ........................................... 14

Preliminary Design for Edible Oil Deployment for T-Area Groundwater .. 17

Issues, Uncertainties and Path Forward........................................................ 21

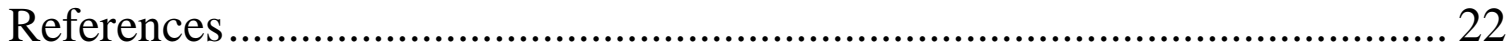




\section{List of Figures}

Figure 1 - T-Area TCE Groundwater Active Plume Footprint ....................................... 3

Figure 2 - Historical TCE Groundwater Concentrations .............................................. 3

Figure 3 - Historical cis-DCE Groundwater Concentrations ......................................... 4

Figure 4 - Schematic of TCE Concentration Reduction Processes .................................. 7

Figure 5 - Microbial Analysis Results from the Bio-Trap Beads .................................. 13

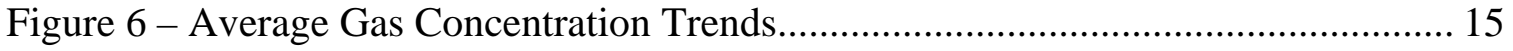

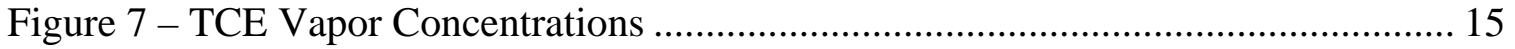

Figure 8 -Co-metabolic Products from Aerobic Degradation of Soybean Oil................. 16

Figure 9 - Schematic Diagram of Neat Oil Deployment............................................. 17

Figure 10 - Schematic Diagram of Emulsified Oil Deployment................................... 18

Figure 11 - T Area Source Zone Detail Area - Neat Oil Treatment Target ................... 19

Figure 12 - T Area Source Zone Detail Area - Emulsified Oil Groundwater Treatment

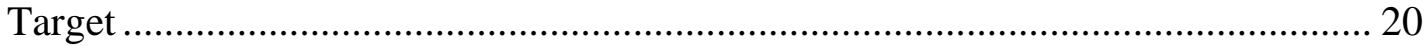




\section{Introduction}

The purpose of these studies was to determine the feasibility of using edible oils for remediation of the low but persistent chlorinated solvent (cVOC) groundwater contamination at the SRS T-Area. The following studies were completed:

1. Review of cVOC degradation processes and edible oil delivery for enhanced bioremediation.

2. Column studies to investigate placing neat oil on top of the water table to increase oil saturation and sequestration.

3. Analysis of T-Area groundwater geochemistry to determine the applicability of edible oils for remediation at this site.

4. Microcosm studies to evaluate biotic and abiotic processes for the T-Area groundwater system and evaluation of the existing microbial community with and with out soybean oil amendments.

5. Monitoring of a surrogate vadose zone site undergoing edible oil remediation at the SRS to understand partitioning and biotransformation products of the soybean oil.

6. Design of a delivery system for neat and emulsified edible oil deployment for the T-Area groundwater plume.

A corresponding white paper is available for each of the studies listed. This paper provides a summary and overview of the studies completed for the remediation of the TArea groundwater plume using edible oils.

This report begins with a summary of the results and a brief description of the preliminary oil deployment design followed by brief descriptions of T-Area and current groundwater conditions as related to edible oil deployment. This is followed by a review of the remediation processes using edible oils and specific results from modeling, field and laboratory studies. Finally, a description of the preliminary design for full scale oil deployment is presented.

\section{Summary of Results}

These studies show very little natural attenuation is occurring and that remediation of the cVOC groundwater plume in T-Area using edible oils for sequestration and bioremediation is appropriate and viable. Oil emplacement along with moderate modifications to the groundwater geochemistry will provide appropriate conditions to change the aquifer to anaerobic and initiate reductive dechlorination of trichloroethylene (TCE). Other degradation processes, co-metabolic and abiotic, are also probable.

The preliminary oil deployment design is proposed as an applied research and development project (treatability study). Using existing wells, approximately 3,000 gallons of neat soybean oil will be floated on top of the water table with the goal of reducing and treating contaminant inputs to the groundwater from the residual contamination in the vadose zone. The dissolved contamination in the groundwater will be treated with circulation of Emulsified Oil Substrate $\left(\operatorname{EOS}^{\circledR}\right)$ between existing well 
pairs. Approximately 4,000 gallons of $\mathrm{EOS}^{\circledR}$ will be deployed using three injection/extraction well pairs. Monitoring is designed to measure appropriate oil placement, maintenance of appropriate geochemistry (neutral $\mathrm{pH}$ ), and attenuation of the TCE groundwater contamination.

The rough cost estimated for this full scale approach, a path to MNA and no further action for cVOCs at T-Area, is $\$ 365 \mathrm{~K}$ which includes monitoring for one year. This estimate assumes SRNL full labor rates and \$125K in materials with a $25 \%$ contingency.

\section{T-Area Background and Groundwater Conditions}

Historically, the cVOCs at T-Area (primarily TCE) have been treated by a combination of active soil vapor extraction and groundwater pump and treat. The former process removed the bulk of the residual vadose zone contamination while the latter contained and reduced the size of the groundwater plume consistent with the interim action goals. All structures have been removed and the site is currently covered by a cap that reduces and controls infiltration and the infrastructure was preserved for continued pump and treat operation. Based on the current state of T Area, deployment of edible oil represents a promising approach to reduce concentrations and facilitate transitioning to a protective condition in which the groundwater plume stabilizes and shrinks passively and which will move naturally toward long-term remedial objectives.

The current size and shape of the T-Area groundwater plume is shown in Figure 1 (TCE data in $\mu \mathrm{g} / \mathrm{l}$ from 4Q05). This area is considered the active plume footprint for remediation with edible oils. Historical TCE groundwater concentrations from wells TBG-3, 4, and 5 are shown in Figure 2. These data show a decrease in concentrations from the pump and treat activities and a concentration stabilization after activities ceased for well TBG-5 which is considered near the heart of the plume. TCE concentrations are still well above the $5 \mu \mathrm{g} / \mathrm{l}$ cleanup up goals.

The presence of cis-DCE (Figure 3) in the plume is promising since it can be a product of reductive dechlorination of TCE. The presence of cis-DCE could indicate reduced (anaerobic) zones in the aquifer and appropriate dechlorinating bacteria that can at a minimum degrade TCE to cis-DCE. The introduction of edible oils should enlarge the anaerobic zones if present, stimulate the microbial activity and increase the rate of TCE destruction and shorten the time to closure. 
WSRC-TR-2006-00363

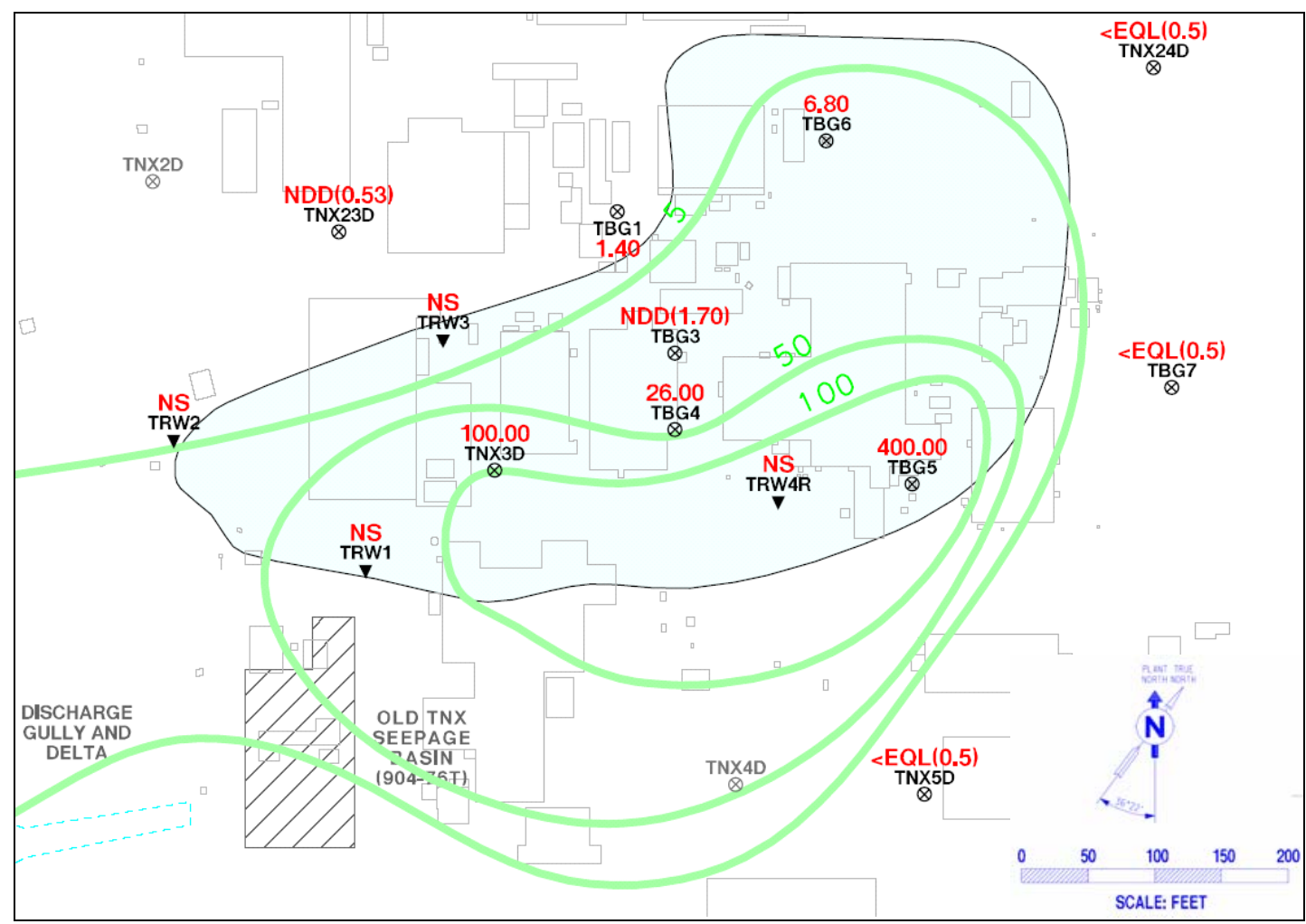

Figure 1 - T-Area TCE Groundwater Active Plume Footprint

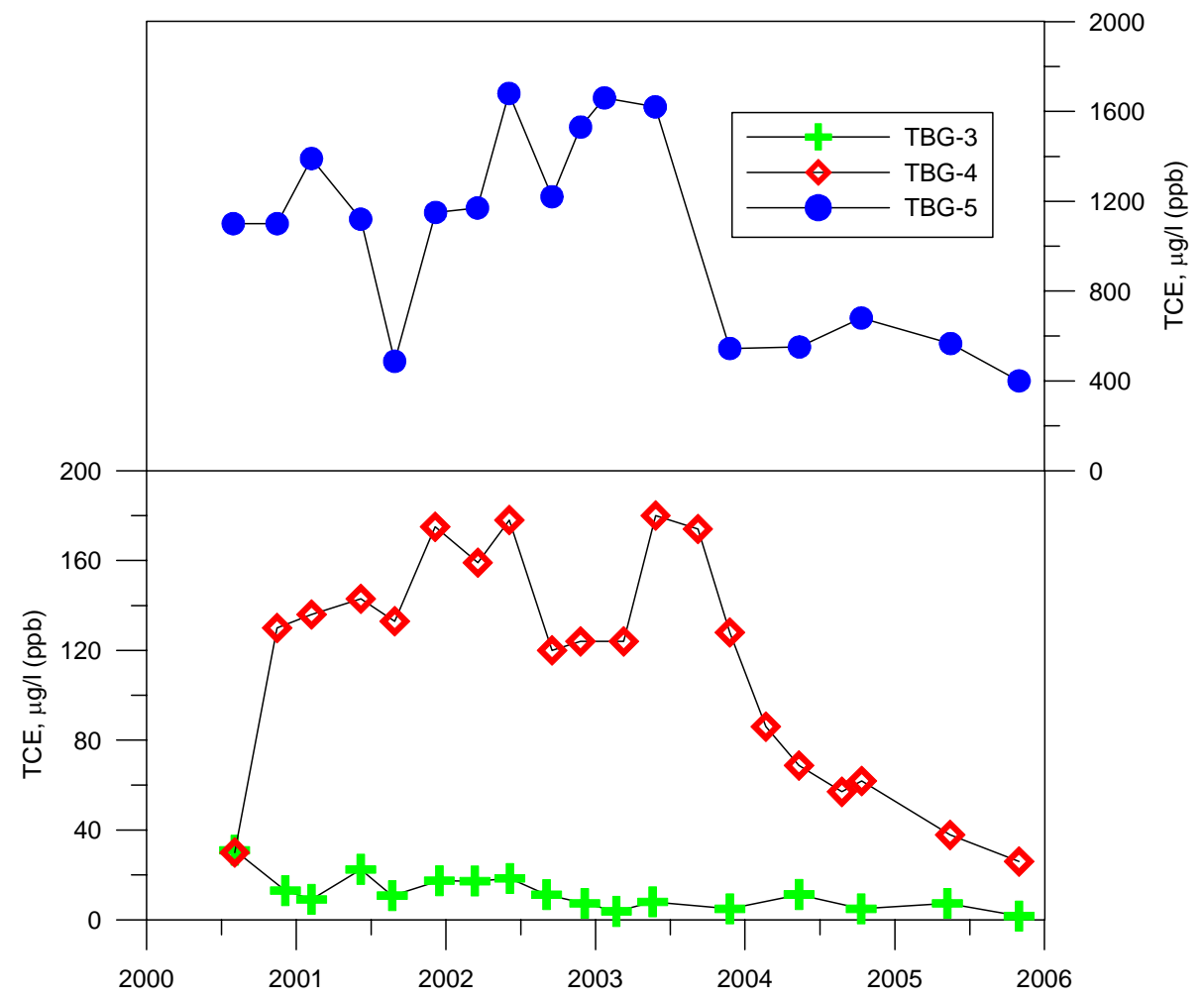

Figure 2 - Historical TCE Groundwater Concentrations 


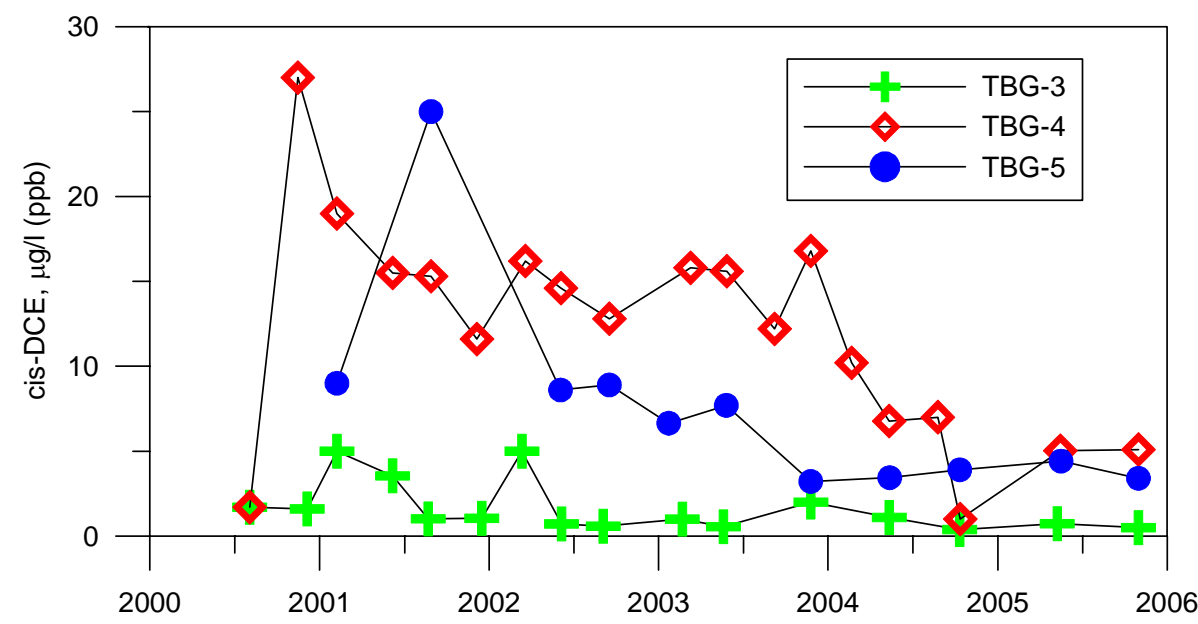

Figure 3 - Historical cis-DCE Groundwater Concentrations

Because of limited geochemical data, wells TBG-3, 4, and 5 in the heart of the TCE plume were sampled on 6/6/06 to obtain the needed parameters to design full scale oil emplacement. The field sampling results are provided in Table 1. All data collected during these studies is provided as an attachment. Only data with impacts for edible oil deployment are discussed in this report.

- The aquifer is currently aerobic based on the dissolved oxygen (DO) values. Reductive dechlorination of TCE will not occur in aerobic systems. Native aerobes can use the oil as a carbon source (electron donor) and dissolved oxygen as the electron acceptor thereby making the aquifer anoxic.

- The initial $\mathrm{pH}$ of T-Area groundwater within the plume is low. This will likely be detrimental to the microbial processes necessary for soybean oil degradation and reductive dechlorination of chlorinated solvents. To raise the $\mathrm{pH}$ to values that promote microbial growth, buffers such as phosphate or sodium hydroxide can be added.

- The groundwater at T-Area has elevated concentrations of nitrate and sulfate, both potential electron acceptors that can interfere with the creation of an anaerobic environment by degradation of the edible oil. Effects of these can be negated by a small increase in the amount of oil deployed. 
WSRC-TR-2006-00363

Table 1 - T-Area Groundwater Field Parameters

\begin{tabular}{|l|c|c|c|c|}
\cline { 2 - 5 } & Parameter & TBG-3 & TBG-4 & TBG-5 \\
\cline { 2 - 5 } & Date & $6 / 6 / 2006$ & $6 / 6 / 2006$ & $6 / 6 / 2006$ \\
\cline { 2 - 5 } & Well Depth, ft & 85 & 80 & 74 \\
\cline { 2 - 5 } & $\begin{array}{l}\text { Water Level (TOC), } \\
\text { ft }\end{array}$ & 62.5 & 60.1 & 55.4 \\
\cline { 2 - 5 } & Start & $13: 20$ & $12: 07$ & $9: 15$ \\
\cline { 2 - 5 } & Stop & $13: 49$ & $12: 45$ & $10: 50$ \\
\hline YSI final & Temp, C & 23.88 & 23.71 & 28.56 \\
\cline { 2 - 5 } & Conductivity, uS/cm & 175 & 284 & 90 \\
\cline { 2 - 5 } & DO, $\%$ & 103 & 102 & 84.7 \\
\cline { 2 - 5 } & DO, mg/l & 8.7 & 8.65 & 6.57 \\
\cline { 2 - 5 } & pH & 5.07 & 3.61 & 4.66 \\
\cline { 2 - 5 } & ORP, mV & 281 & 360 & 280 \\
\hline & Ammonia, mg/l & 0.05 & 0.73 & 0.11 \\
\cline { 2 - 5 } & Soluble iron, mg/l & 0.07 & 0.48 & 0.18 \\
\cline { 2 - 5 } & Phosphate, ppm & 0.26 & 0.67 & 0.97 \\
\cline { 2 - 5 } & Nitrate, ppm & 39.04 & ND & 9.23 \\
\cline { 2 - 5 } & Oxygen, mg/l & 8.1 & 9.21 & 7.03 \\
\cline { 2 - 5 } & Total Alkalinity & ND & ND & ND \\
\cline { 2 - 5 } & Sulfate, ppm & 32.96 & 32.4 & 5.94 \\
\hline
\end{tabular}




\section{Review of Edible Oil Remediation Processes}

Edible oils have emerged as an effective treatment at environmental waste sites as a way to enhance anaerobic bioremediation and sequestration of chlorinated solvents and related contaminants in the saturated zone. Traditionally, active remedial approaches such as pump and treat and/or air sparging techniques have been applied at these sites to decrease chlorinated compound concentrations in saturated zones but have proven unsuccessful for final remediation where mass transfer limitations exist.

Use of edible oils at sites with relatively low contaminant concentrations has proven to be a cost-effective alternative for treatment of residual contamination in the saturated zone. Edible oil deployment serves to decrease chlorinated compound concentrations in two ways: 1) physical sequestration, which reduces effective aqueous concentration and mobility; and 2) stimulation of anaerobic degradation of the contaminants to less toxic and/or more readily biodegradable compounds.

Biodegradation of an organic substrate such as soybean oil depletes the aquifer of oxygen and other terminal electron acceptors and creates conditions conducive to anaerobic degradation processes. The organic substrate is fermented to produce hydrogen, which is used as an electron donor for anaerobic dechlorination. TCE degrades fairly readily once anaerobic conditions are created. However, specific organisms (Dehalococcoides) need to be present to degrade these solvents completely to ethene.

\section{Fate of Soybean oil in an Aquifer}

When edible oils and nutrients are put into an aerobic aquifer, native aerobes will use the oil as a carbon source (electron donor) and dissolved oxygen as the electron acceptor. The rate of oxygen depletion will depend on the initial biomass and should increase over time eventually depleting the aquifer of oxygen.

Edible oils can then be anaerobically fermented to hydrogen and acetate through a twostep process where the oil is first hydrolyzed releasing free fatty acids and glycerol to solution. The glycerol then degrades to 1,3-propanediol and subsequently to acetate. Saturated fatty acids undergo further breakdown by beta-oxidation resulting in the formation of hydrogen $\left(\mathrm{H}_{2}\right)$, acetic acid $\left(\mathrm{H}_{2} \mathrm{C}_{2} \mathrm{H}_{3} \mathrm{O}_{2}^{-}\right)$, and the original molecule of acid appears as a new acid derivative with two less carbon atoms. By successive oxidation, long-chain fatty acids are whittled into progressively shorter fatty acids and acetic acid. Four hydrogen atoms are released from saturated fatty acids for each acetic acid unit produced (Sawyer, McCarty et al., 1994). Unsaturated fatty acids undergo the same general process, but release two atoms of hydrogen for each acetic acid unit.

Acetic acid and hydrogen produced in the subsurface by fermentation of edible oils will be consumed in a variety of different reactions. If high-energy electron acceptors such as oxygen and nitrate are present, the hydrogen and acetic acid will be very rapidly oxidized to carbon dioxide and water. Once these materials are consumed, excess hydrogen and acetate can then be used to reduce sulfate and oxidized forms of manganese and iron in 
the sediments, and for reductive dechlorination. Excess hydrogen and acetic acid will also be fermented to methane and carbon dioxide.

\section{TCE Concentration Reduction Processes}

The addition of edible oils to the groundwater plume will reduce TCE groundwater concentrations through partitioning/sequestration and biotic and abiotic degradation. Biotic degradation can occur by direct dechlorination and by cometabolic processes. All of these processes will likely occur to some extent. Oil deployment will create an anaerobic zone through initial aerobic oil degradation with a down gradient aerobic zone as depicted in Figure 4. The TCE concentration reduction processes are labeled in green along with their corresponding breakdown products. These processes are discussed in more detail below.

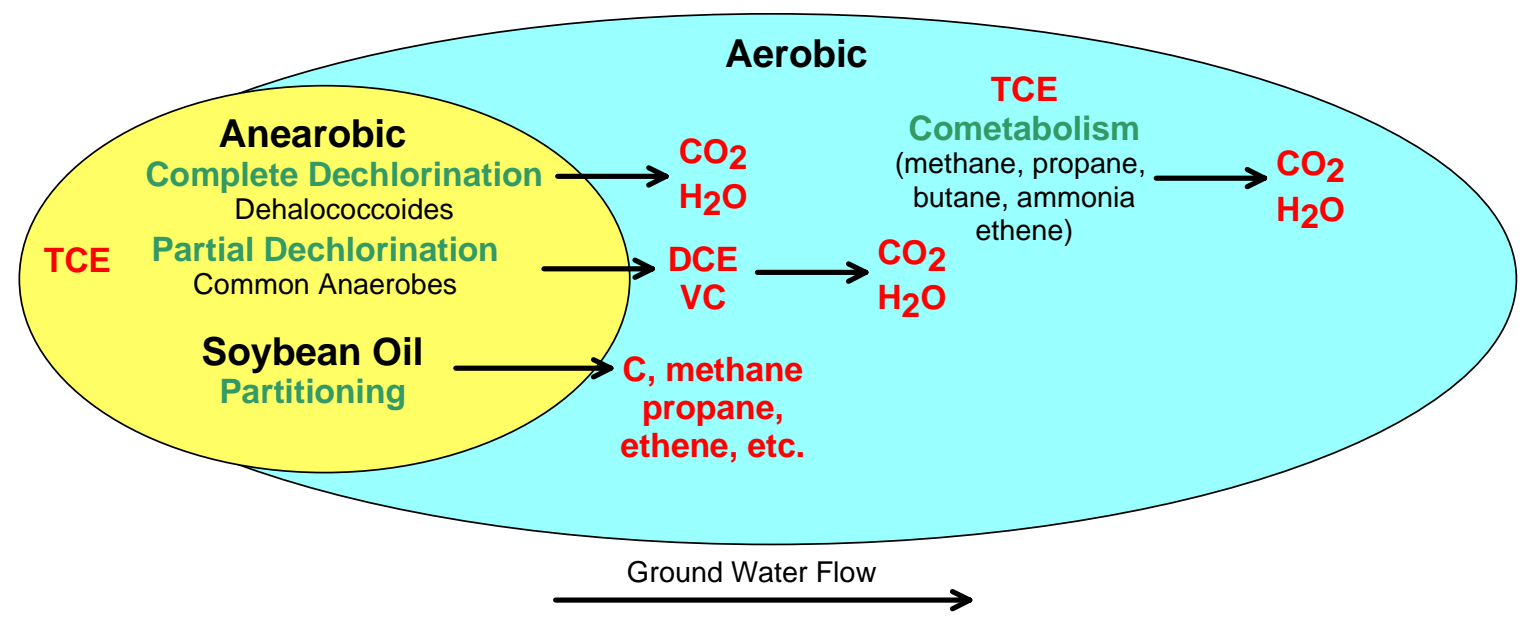

Figure 4 - Schematic of TCE Concentration Reduction Processes

\section{TCE Partitioning/Sequestration}

The impact of chlorinated solvent partitioning into edible oil on aqueous phase concentrations can be described using a standard linear equilibrium partitioning approach. In general, dissolved chlorinated solvents in groundwater such as TCE will preferentially partition into soybean oil because both compounds are non-polar (hydrophobic). This partitioning sequesters the TCE and decreases groundwater concentrations.

Partitioning of cVOCs between water and soybean oil has been studied and shown to be linear. Partitioning coefficients $\left(\mathrm{K}_{\mathrm{p}}\right)$ are higher for the more hydrophobic compounds and were similar to literature values of the octanol-water partition coefficient $\left(\mathrm{K}_{\mathrm{ow}}\right)$ (Pfeiffer, Bielefeldt et al., 2005).

Based on SRNL laboratory studies and literature $\mathrm{K}_{\mathrm{p}}$ values, approximately 0.8 lbs of TCE will partition into 1 gallon of soybean oil with a corresponding groundwater concentration of $0.005 \mathrm{mg} / \mathrm{l}$. This partitioning quickly decreases solvent concentrations 
in groundwater and soil gas and locates the solvents in the most active biological areas of the aquifer. In the saturated zone, dissolved TCE will migrate to the oil by both advective and diffusive mechanisms.

\section{TCE Destruction - Anaerobic Reductive Dechlorination}

Chlorinated solvents can be naturally degraded by microorganisms by cometabolism or when used as an electron donor (Borden, 2000). However, the most common and fastest degradation pathway is a process called reductive dechlorination, dechlororespiration, or reductive dehalogenation. Reductive dechlorination is an anaerobic process in which the chlorinated compounds serve as the terminal electron acceptors (Borden, 2000), as opposed to oxygen, which is the terminal electron acceptor during aerobic respiration. The dehalogenation process involves removing a chlorine atom from the alkene molecule, and replacing it with a hydrogen atom (Major, 2002). Edible oil addition enhances reductive dechlorination efficiency by providing the bacteria with a carbon source that is required for macromolecule production, and an electron donor that is required for energy production. Lack of suitable carbon sources and electron donors is often the limiting factor for biodegradation in formations below the root zone (Hunter, 2005).

The degradation sequence of chlorinated compounds starting with PCE is (Sutherson, 2002):

$\mathrm{PCE} \longrightarrow \mathrm{TCE} \longrightarrow \mathrm{C}-\mathrm{DCE} \longrightarrow \mathrm{VC} \longrightarrow$ Ethene $\longrightarrow$ Ethane $\longrightarrow$ Carbon dioxide and Water

In the reductive dechlorination process, microorganisms replace chlorine atoms with hydrogen, forming more reduced products. In this process, where tetrachloroethene (PCE) is subsequently reduced to trichloroethene (TCE), 1,2-cis-dichloroethene (c-DCE), vinyl chloride (VC), and eventually to, the non-toxic end products, ethene and ethane. Highly chlorinated compounds (i.e. PCE) are more susceptible to reductive dechlorination than less chlorinated compounds (i.e. VC) because they are more oxidized. Therefore, microorganisms that carry out the conversion of PCE to TCE to cis-DCE are relatively common and can survive in a variety of environments.

The only known microorganism that can carry out the complete anaerobic conversion of PCE to ethane is Dehalococcoides ethenogenes or DHC. However this species is not always present and only grows well under strongly reducing, methanogenic conditions. Termination of the reductive dechlorination process at cis-DCE in the anaerobic treatment zone is not necessarily a problem. While cis-DCE is relatively difficult to degrade anaerobically, it is fairly easy to biodegrade aerobically (McCarty, 2002). Therefore, as cis-DCE migrates out of the anaerobic treatment zone, it will mix with oxygen and should rapidly degrade (Lee, 2004).

\section{TCE Destruction - Cometabolism}

The literature clearly shows the ability of aerobic cometabolism to remediate low solvent concentrations ( $<1 \mathrm{mg} / \mathrm{l} \mathrm{TCE})$ in groundwater to non-toxic end products $\left(\mathrm{CO}_{2}\right.$ and $\left.\mathrm{Cl}^{-}\right)$. Cometabolism is defined as the metabolic transformation of a substance while a second 
substance serves as the primary energy or carbon source. Cometabolic bioremediation relies on a primary substrate (electron donor) dissolved oxygen (electron acceptor), nutrients and the appropriate microorganisms. Cometabolic organisms for TCE destruction use other growth substrates (methane, propane, butane, ethene, ammonia, etc.) to produce enzymes capable of degrading TCE to the end product $\mathrm{CO}_{2}$ (Arp, Yeager et al., 2001). Anaerobic reductive dechlorination usually occurs at rates that are orders of magnitude faster than cometabolic processes (Freeborn, West et al., 2005).

\section{Sequestration and Biodegradation Synergy}

Chlorinated solvents are typically found in the subsurface in four main forms:

NAPL(Non-Aqueous Phase Liquid), soil vapor, in solution (water), or adsorbed. In the case where an organic substrate such as edible oil is present there will also be a mass in solution within the oil. The contaminant concentration present in any one of these states is in constant dynamic equilibrium with contaminant concentration in all of the other states. The relative equilibrium concentrations are characterized using fugacity constants (solubility, Henry's constant, and adsorption constant). If the contaminant concentration in one phase is affected, then the concentrations in the other phases will adjust until the fugacity constants are satisfied, and a new equilibrium is reached between all of the phases.

Bacteria only exist in water; therefore, the only chlorinated solvent mass that is available for biodegradation is the mass that is in aqueous solution. As the contaminant molecules in the water are destroyed they are replaced by molecules from the other phases. This chemical equilibrium process allows for the contaminant in all forms to be destroyed if the system is maintained for an appropriate period of time.

\section{TCE Destruction - Abiotic}

Although reductive dechlorination is seen as the primary destructive process of TCE, abiotic destruction processes will also likely play a role. The addition of an organic substrate and presence of iron and sulfate alone will typically result in the formation of reactive iron sulfides due to the biological process of iron and sulfate reduction. The reaction product is acetylene with an intermediate of 1,1-DCE. The acetylene is then used by aerobes to further reduce oxygen (DOD, 2004)

\section{Review of the Theory and State of the Practice for Edible Oil Delivery}

The goal of edible oil emplacement typically has been to create a reactive barrier within, or downstream of, the contaminated portion of an aquifer (Hunter, 2005). Once in place, the contaminant is removed from groundwater as it flows through the stationary barrier due to natural hydraulic gradients. In order for this process to occur, the substrate within the barrier must be present at saturations that will allow for long term bio-stimulation $(0.5$ to $2 \%$ ), it must be relatively immobile, and permeability must be great enough to allow water to flow through the barrier rather than flow around (Coulibaly and Borden, 2004).

Traditionally, these barriers have been emplaced by injecting non-aqueous phase liquid (NAPL) oils into the saturated zone using conventional wells or temporary direct push points (Lee, Buchanan et al., 2000). NAPL injection results in high saturations but 
severely decreases the aquifer permeability. The radius of injection into wells is usually limited to tens of feet and can create barriers where groundwater flows around the reactive zone.

Edible oils can also be distributed in the subsurface as oil-in-water emulsions. The oil droplets in oil-in-water emulsions are already dispersed in the water phase, making them completely miscible with water. This, along with the fact that emulsions are much less viscous than oil NAPL, allows for lower injection pressures. As the oil droplets are transported through the formation pore spaces, they collide with sediment surfaces and stick. The sediment surfaces gradually become coated with a layer of oil droplets.

To maximize the potential for success in T Area (where deployment zone distances are on the order of $100 \mathrm{ft}$ using existing wells), EOS $^{\circledR}$, a product that has been successfully deployed over such distances in similar geologic materials (Kovacich, Beck et al., 2006), was selected for the preliminary design. Because of the small droplet sizes and negative surface charges on the droplets, research on EOS $^{\circledR}$ suggests that the oil deployment is not predicted by filtration concepts, but rather by collision and oil retention capacity relationships (Coulibaly and Borden, 2003; Jung and Borden, 2003; Birk, Borden et al., 2006). The research further suggests that the deployment of a properly prepared emulsion is insensitive to the premixing versus injection and then chasing with water (the resulting oil distributions are equivalent). 


\section{Studies to Specifically Support Edible Oil Deployment at T-Area}

\section{Column Studies to Support NAPL Oil Deployment on the Water Table}

The purpose of the column studies was to investigate the possibility of using fluctuations in a water table to effectively distribute NAPL edible oils for contaminant sequestration and biostimulation purposes. Daily water table fluctuations of some scale will occur naturally at most sites. These fluctuations are typically rather small (on the order of mm or $\mathrm{cm}$ ). Local ground water levels can also be affected by pumping or injecting into wells, or by installation of low permeability caps that would cause a decrease in water table elevation.

Edible oils, such as vegetable oil and other LNAPLS (Light non-aqueous phase liquids), will tend to pool and spread at the water table surface if they released either into the vadose zone or as a NAPL below the water table. Water table fluctuations should cause floating LNAPL to be redistributed in the subsurface in what is called a "smear zone"

The results of the column experiments suggest that water table fluctuations with a vegetable oil lens present at the water table surface can be a viable way of distributing substrate for contaminant sequestration and biostimulation purposes. Column sample analyses indicate that residual oil saturations within the saturated zone tend to range between at least 0.08 and 0.12 , which would be ideal for long term biostimulation without significant reductions in formation permeability.

The full scale objective of these studies is to intercept and reduce future cVOC inputs to the groundwater. This is accomplished as the oil flows downward and then spreads out, forming a relatively thin but laterally extensive layer at the water table surface. This deployed oil reduces cVOC loading to the groundwater by two mechanisms. First, the oil has a high affinity for the cVOC, so that the clean oil will remove a large amount of cVOC through direct partitioning and will significantly depress the adjacent groundwater and soil gas concentrations. Second, the oil serves as an electron donor in the pathways for reductive cVOC biodegradation. The deployed oil also has an indirect benefit for downgradient cVOC degradation. By generating conditions for removing oxygen, nitrate and sulfate, the water emanating from the neat oil deployment zone has lower levels of these competing electron acceptors and is better suited to downgradient reductive cVOC biodegradation within the plume flowpath. A final benefit of the neat oil deployment at the water table is its creative exploitation of the physical properties of the oil and the structure of the water table to spread the oil over a large area and generate a treatment zone of optimum geometry

\section{Geochemical Effects on Edible Oil Deployment for T-Area Groundwater}

The geochemistry of a groundwater system can affect the deployment of edible oil to clean up chlorinated solvent contamination in two ways. The mass of electron acceptors in the groundwater and aquifer sediments can influence the efficiency of the deployment. If there is a large mass of electron acceptors, more oil will be required to achieve the same effectiveness and longevity of treatment. Secondly, the magnitude of collateral 
effects, unintended and possibly detrimental effects to water quality, depends on the chemistry of the groundwater and aquifer sediments

The initial $\mathrm{pH}$ of $\mathrm{T}$-Area groundwater within the plume is low and the $\mathrm{pH}$ will remain low during soybean oil degradation if appropriate electron acceptors are not present or do not react to buffer the system. This will likely be detrimental to the microbial processes necessary for soybean oil degradation and reductive dechlorination of chlorinated solvents. Buffers such as phosphate or sodium hydroxide should be added to raise the $\mathrm{pH}$ to values that promote microbial growth,.

The geochemistry of groundwater and aquifer sediments at T-Area does not preclude the use of soybean oil to promote reductive dechlorination of dissolved solvents. There are terminal electron acceptors present $-\mathrm{NO}_{3}{ }^{-}$and $\mathrm{SO}_{4}{ }^{-2}$ in groundwater and $\mathrm{Fe}(\mathrm{III})$ and Mn(III or IV) oxides in sediment - but simulations indicate that the effects of these can be negated by a small increase in the amount of oil deployed.

Generation of undesirable aqueous species such as $\mathrm{Fe}^{+2}, \mathrm{Mn}^{+2}$, and $\mathrm{NH}_{4}^{+}$will occur, but will not likely present any collateral environmental problem.

To optimize performance of soybean oil deployment at T-Area, laboratory studies could be performed to assess the affect of electron acceptors on performance. In addition, the use of $\mathrm{NaOH}$ or $\mathrm{Na}_{3} \mathrm{PO}_{4}$ to elevate the initial $\mathrm{pH}$ could be evaluated with laboratory studies using existing core material and real or simulated groundwater.

\section{Microbial Communities and Microcosm Studies for T-Area Groundwater}

Microbial Insights Bio-Trap ${ }^{\circledR}$ sampler is a passive sampler for collecting existing microbial communities in water wells. Analysis of the sample will determine if appropriate degrading bacteria are present. Analyses included known dechlorinating bacteria and the bacteria groups methanogens, methanotrophs, and iron/sulfate reducers. Five samplers were deployed with two 'baited' with Enhanced Oil Substrate (EOS ${ }^{\circledR}$ ) oil for 60 days in well TBG-5.

Analysis of the Bio-Trap ${ }^{\circledR}$ beads was performed by Microbial Insights Inc.

Dehalococcoides (DHC) and iron/sulfate reducing bacteria (IRB/SRB) were not detected by the Polymerase Chain Reaction (PCR) based methods used. Methanogenic (MGN) and methanotrophic (MOB) bacteria, however, were quite abundant. In all cases, EOS ${ }^{\circledR}$ baited beads resulted in the enrichment (1 order of magnitude) of both of these bacterial groups relative to the unbaited control beads. See Figure 5 and note log scale. It is possible that the methanogens and methanotrophs are operating synergistically in a tightly coupled carbon/energy cycle which creates suitable habitat for both processes. These results provide a snap shot of the types of bacteria that are present in the aquifer and capable of colonizing surfaces. The results also indicate that EOS ${ }^{\circledR}$ will stimulate bacterial cell growth in this aquifer system. 


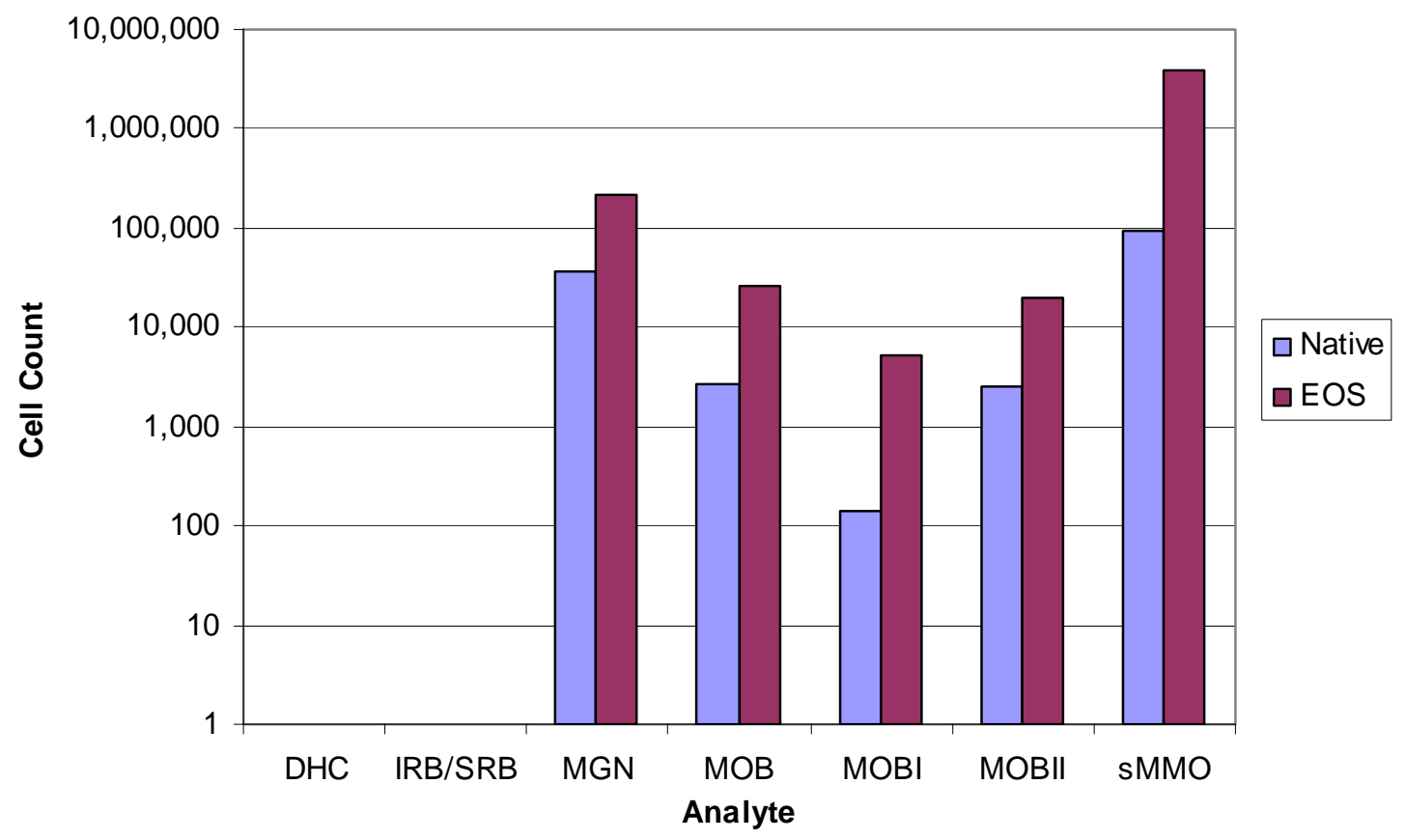

Figure 5 - Microbial Analysis Results from the Bio-Trap Beads

Soluble methane monooxygenase (sMMO) is the functional enzyme of the methanotrophs that catalyzes TCE oxidation. Methanotrophs can aerobically cometabolize TCE to an epoxide intermediate which then reacts to form dichloroacetic acid. This compound can proceed through typical intermediate metabolic pathways for complete degradation. Methanogens can anaerobically cometabolize (via metalloproteins) polychlorinated ethenes to cis-DCE, but VC, ethene and ethane, and acetylene are also possibilities.

The microcosm experiments were designed to explore the biological potential for TCE degradation at T-Area using archived T-Area soil and fresh groundwater. Edible oil substrate, EOS ${ }^{\circledR}$, was introduced as the carbon and energy source. Site groundwater was combined with $\operatorname{EOS}^{\circledR}$ (10:1) and then $\mathrm{pH}$ adjusted with $\mathrm{NaOH}$ to 5.5 (site relevant $\mathrm{pH}$ ) and 7.0 (optimal for biological activity). T-Area subsurface groundwater derived bacteria were obtained using Bio-Trap ${ }^{\circledR}$ samplers. Headspace gases were analyzed $(\mathrm{t}=0$ and 50 days) for ethene, ethane, and the chlorinated ethenes by GC/MS.

The microcosm experiments performed in this study provided no immediate evidence for the biological degradation of TCE. This should not be taken to suggest that biological degradation processes could not participate in field scale remediation efforts at T-Area, but rather would likely require alteration of subsurface conditions (i.e., introduction of EOS $^{\circledR}$ ) and time in order to recruit the appropriate bacteria (i.e., fermentative bacteria, dechlorinators) in sufficient biomass before these processes could be quantifiable and self-sustaining. An SRS isolated strain of Dehalococcoides is available and can also be introduced once the aquifer reaches appropriate conditions (anaerobic and neutral $\mathrm{pH}$ ). 
Additional experiments were designed to explore abiotic reduction of TCE and determine whether abiotic degradation products differed from those produced by biological mechanisms. Microcosms were created using chemically reduced T-Area soil with 5.0 $\mathrm{mg} / \mathrm{l} \mathrm{TCE}$ in water. Controls $(\mathrm{n}=6)$ included unreduced soil and TCE only treatments. Headspace gases were analyzed at 14 days.

These results indicate that in a strongly reducing environment, TCE can be dechlorinated, though not completely, to 1,1-DCE. It was expected that reduced iron present in the soil could serve as reductant for TCE. The T-Area soil used in this study contained $0.11 \mathrm{mM}$ of acid labile $\mathrm{Fe}^{2}+/ \mathrm{g}$ (Ferrozine Assay $^{3}$, 562nm).

\section{Soybean Oil Deployment Results for Surrogate SRS Site}

Soybean oil (660 gal) was injected into the vadose zone as a research study to evaluate the effectiveness of edible oils for solvent sequestration and the ability to change a vadose system from aerobic to anaerobic to initiate reductive dechlorination. This site, located in the SRS M-Area, was used as a surrogate for the T-Area groundwater to aid in understanding the partitioning and biotransformation products of the soybean oil in similar type sediments. Byproducts from the biotransformation of the soybean oil are important because they provide compounds for co-metabolic transformations of TCE.

Gas sampling was the cornerstone for this evaluation. Analyses for cVOCs and biotransformation products were performed including $\mathrm{CO}_{2}, \mathrm{O}_{2}$, TCE, PCE, cis-DCE, vinyl chloride, methane, ethane and ethene. The average gas trends from the surrogate site are shown in Figure 6. The concentration data is normalized and the dashed vertical lines are the dates of soybean oil injections. The data show rapid and continued partitioning of TCE into the soybean oil. The utilization of the oil as a carbon source by aerobic bacteria is proven by the decrease in $\mathrm{O}_{2}$ and increase in $\mathrm{CO}_{2}$. Overall, the TCE concentration/flux reduction was $60 \%$ in this vadose zone setting.

TCE concentration trends from individual monitoring points are shown in Figure 7. The monitoring points with the fastest decrease in concentration are closest to the oil deployed in the subsurface. Concentrations in the more distal monitoring points decrease at a slower rate. Overall, the data indicate the TCE vapor is reaching equilibrium towards the average (heavy red line) as the TCE partitions into the oil.

Aerobic degradation of the soybean oil produced the beneficial co-metabolic products methane, propane, butane, ethene and ethane as shown in Figure 8. The increase of the co-metabolites is encouraging since they are also likely being consumed as they are produced. These compounds will provide a secondary aerobic co-metabolic treatment zone for TCE in the T-Area groundwater down gradient of the oil injection/anaerobic treatment zone.

Destruction of TCE by biotic or abiotic process could not be verified at the surrogate site. No reductive dechlorination products of TCE (cis-DCE, VC) were measured. The system was not completely anaearobic but it is hypothesized that anaerobic zones were present. cis-DCE and VC are easily degraded in aerobic systems and also have fairly high 
detection limits with the analysis methods used. Co-metabolic breakdown products are not volatile and could not be measured from the vadose zone sampling regime. TCE breakdown products will be easier to sample and measure in groundwater.

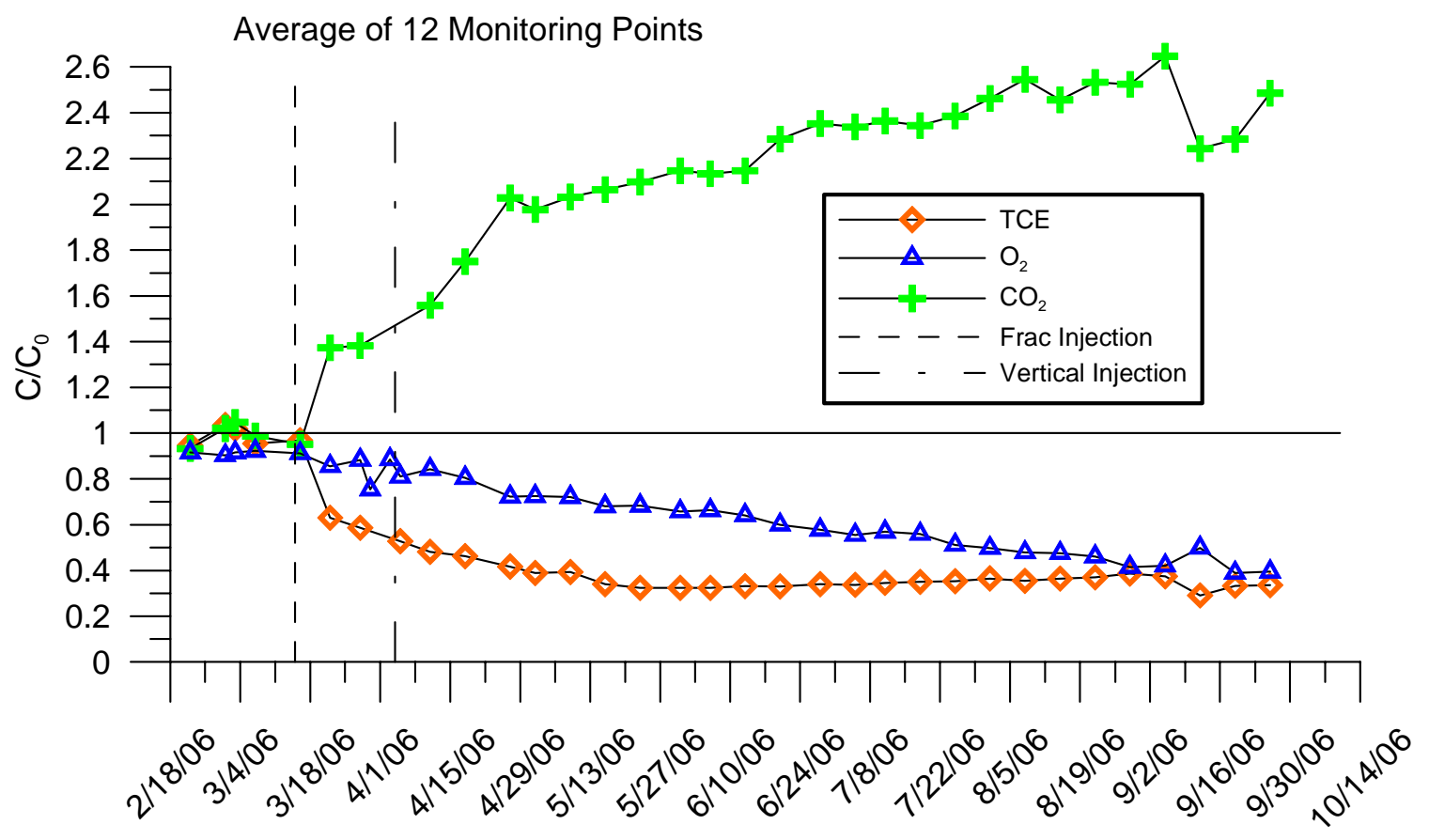

Figure 6 - Average Gas Concentration Trends

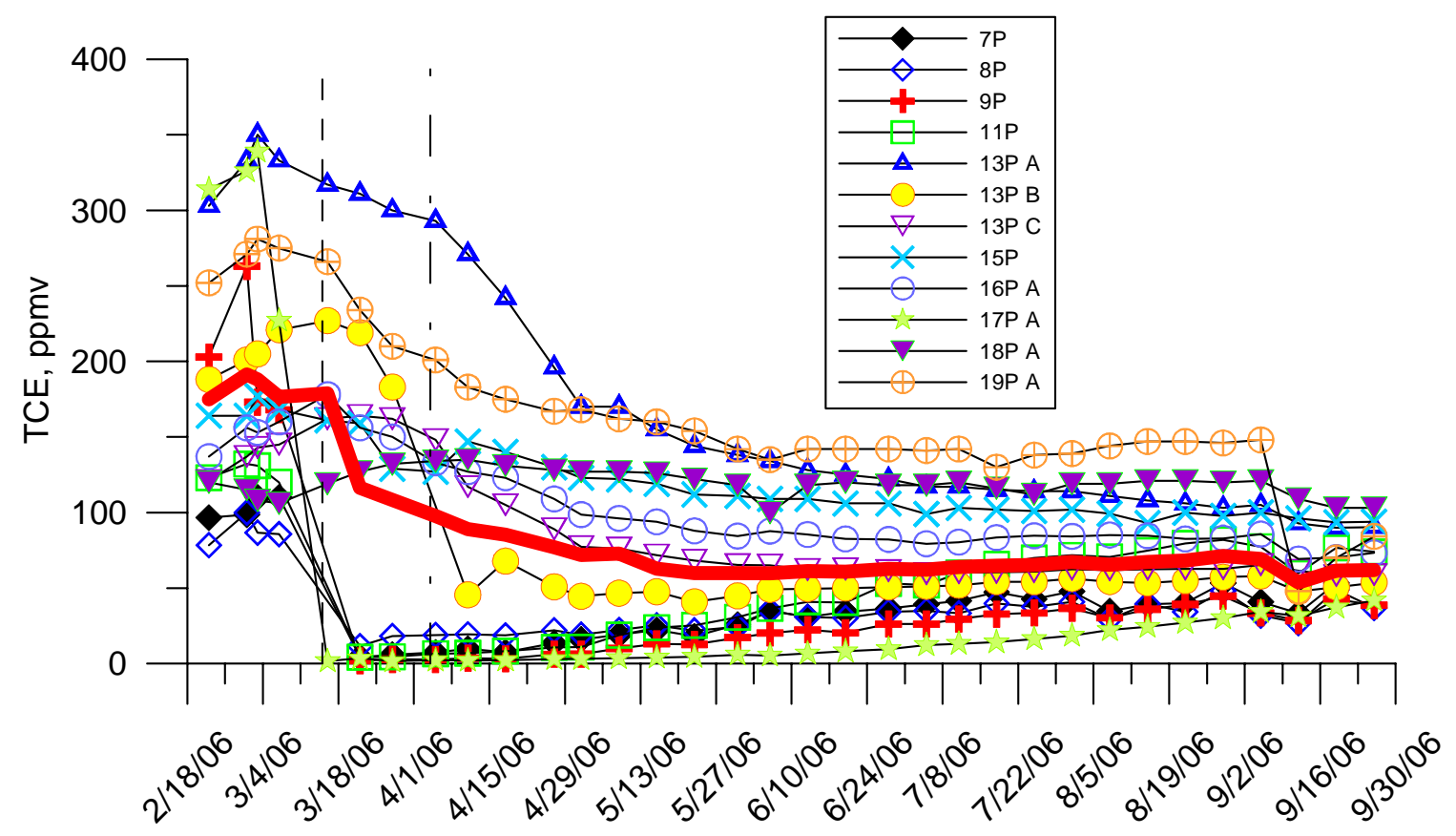

Figure 7 - TCE Vapor Concentrations 


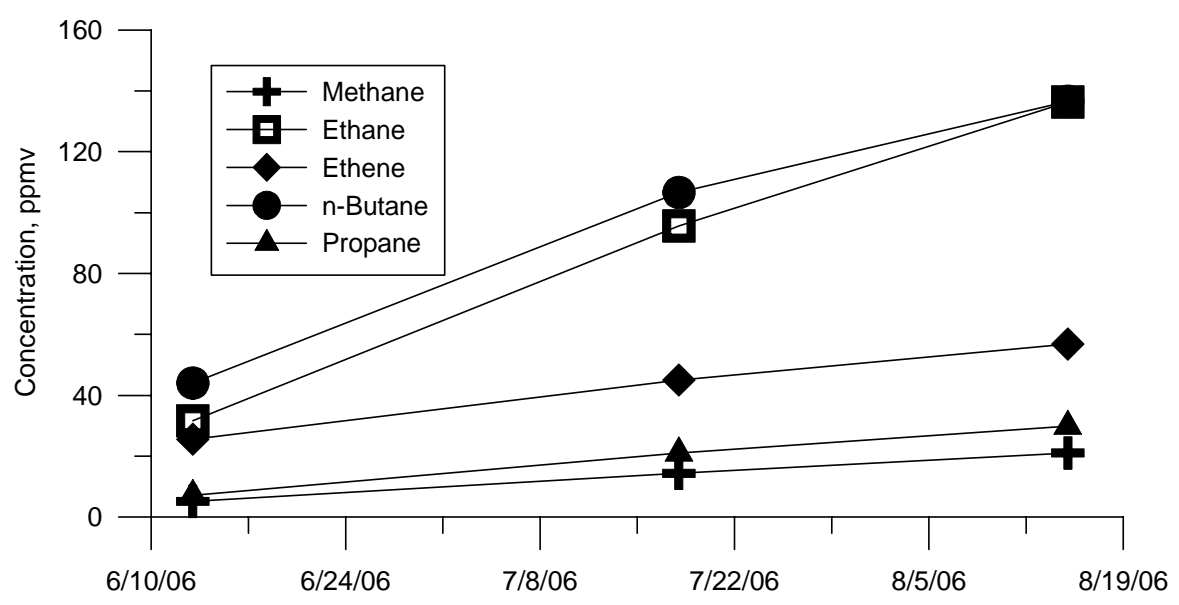

Figure 8 -Co-metabolic Products from Aerobic Degradation of Soybean Oil

The following conclusions can be drawn from data from the surrogate site:

- Soybean oil will attract and sequester TCE in the subsurface.

- Concentration reduction in the vadose zone is rapid. The same trends are expected in the saturated zone but will likely occur at a slower rate because gas diffusion is a much more rapid process.

- Soybean oil can transform an aerobic system to an anaerobic system thus promoting anaerobic reductive dechlorination of TCE.

- Nutrients will need to be added to SRS sediments to promote and accelerate bioactivity. Bio-transformation of the soybean oil has slowed down indicating macro-nutrients are limited $(\mathrm{N}, \mathrm{P})$. Bio-activity products $\left(\mathrm{O}_{2}\right.$ and $\left.\mathrm{CO}_{2}\right)$ generation has decreased over time but sequestration has remained stable.

- The initial aerobic degradation of soybean oil will produce beneficial cometabolites to degrade TCE in the down gradient aerobic zone. 


\section{Preliminary Design for Edible Oil Deployment for T-Area Groundwater}

The result of the design process was a two part deployment: 1) neat (pure) vegetable oil at the water table in the residual source area, and 2) emulsified vegetable oil in the core of the groundwater cVOC plume using existing wells. In the first part, neat oil spreads laterally forming a thin layer on the water table to intercept and reduce future cVOC input from the vadose zone (Figure 9). In the second part, emulsified oil serves to stimulate formation of an active bioremediation "reactor" within the active plume footprint to degrade existing groundwater contamination and any future inputs (Figure 10). For purposes of this preliminary design, pure soybean oil was assumed for the neat oil and a commercially available remediation product $\left(\right.$ EOS $^{\circledR} 5998$ B42) was assumed for the emulsified oil. The enhanced oil substrate $\left(\operatorname{EOS}^{\circledR}\right)$ has properties suitable to the wide distribution needed to use existing wells and includes nutrients (e.g., vitamin B12) that are beneficial for the biodegradation of cVOCs. Additional reagents (e.g., to stabilize $\mathrm{pH}$ ) and microbial inoculants may also be required. The full preliminary design is provided as a separate white paper.

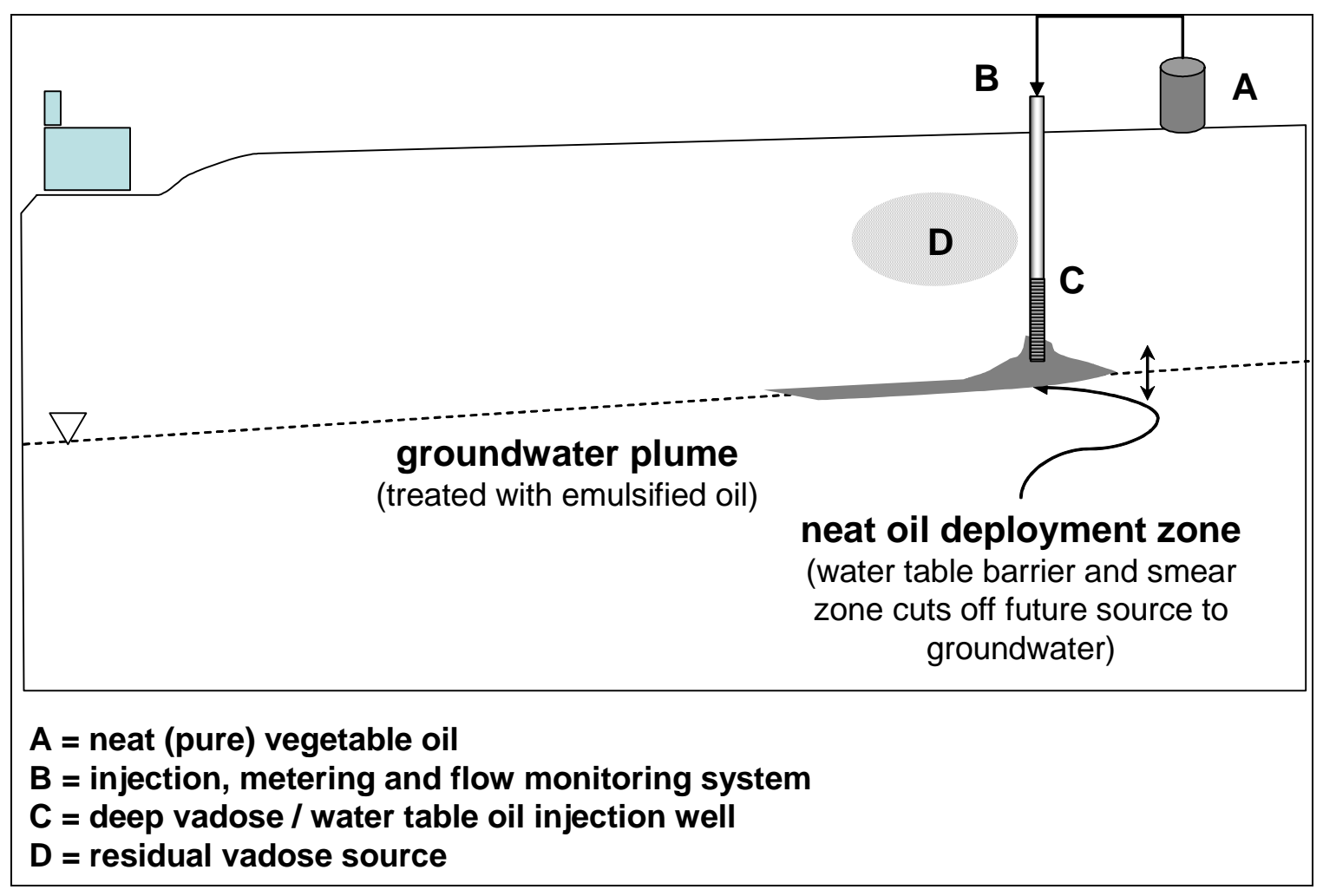

Figure 9 - Schematic Diagram of Neat Oil Deployment 


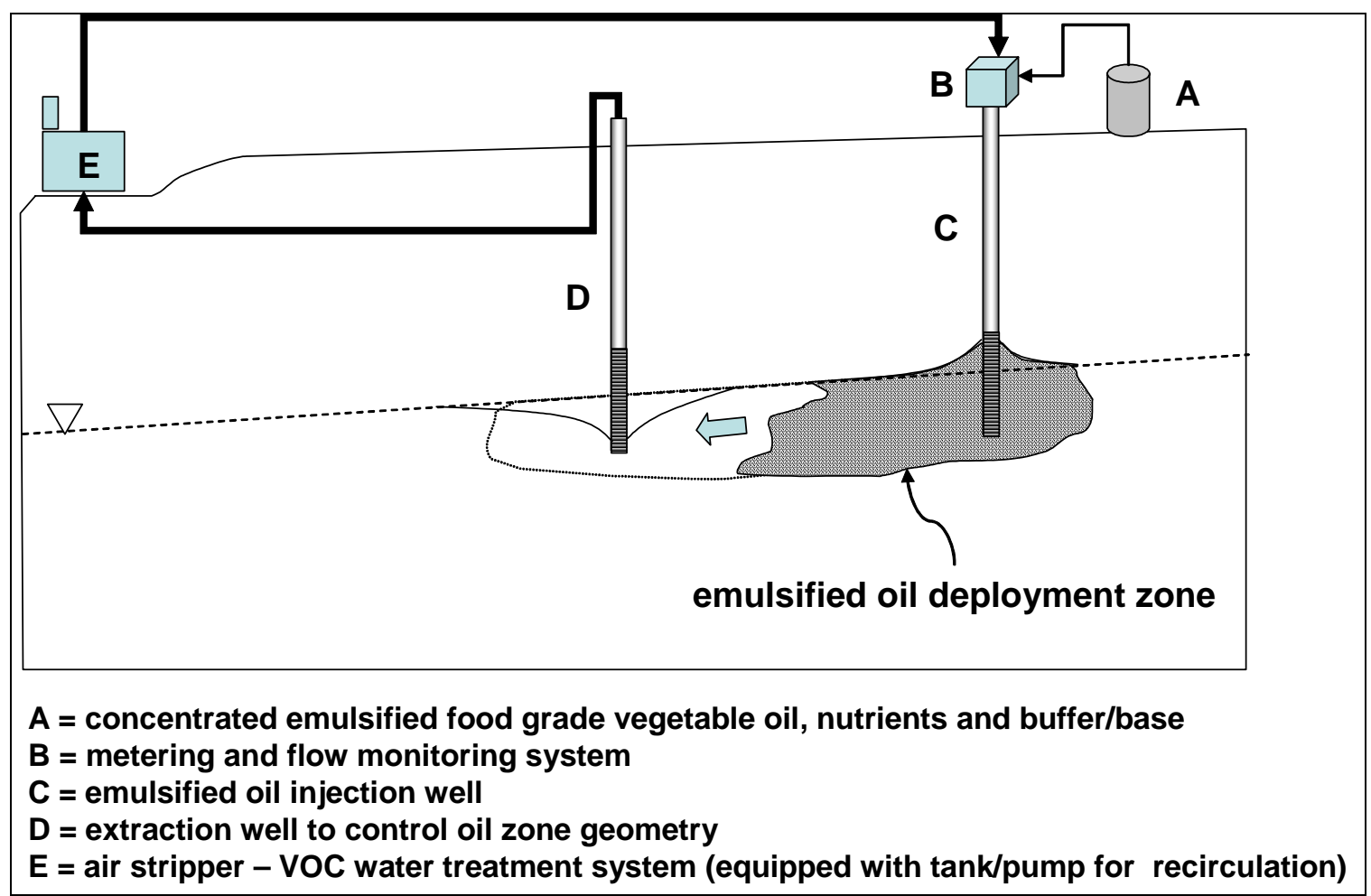

Figure 10 - Schematic Diagram of Emulsified Oil Deployment

The key summary parameters for full scale deployment are as follows:

Neat Oil at the Water Table (Figure 11):

- Description of deployment: Emplace a thin sheet of oil at the water table beneath residual vadose sources using selected deep vadose wells that are completed just above the water table. The deployment relies on the characteristics of the oil (density and transport properties) to move it into the desired configuration.

- Quantity of oil: approximately 2800 gallons (53 drums)

- Existing wells used in deployment: TVX3L, TVX5L and either TVX6L or dry screen in TBG5

- Approximate field time needed for deployment: One week followed by monitoring

EOS $^{\circledR}$ in the Groundwater Plume (Figure 12):

- Description of deployment: Water would be extracted from a down gradient well, treated and reinjected in an up gradient well fitted with and EOS $^{\circledR}$ metering system. In each injection-extraction pair, the operation would continue until the desired EOS $^{\circledR}$ is injected along with sufficient water to distribute the EOS $^{\circledR}$ throughout the entire volume between the wells.

- Quantity of $\operatorname{EOS}^{\circledR}: 30,000$ lbs (71 drums)

- Total quantity of water pumped: 200,000 gallons

- Existing wells used in deployment: Deployed sequentially using injection extraction pairs (TBG5 $\rightarrow$ TRW-4R, TRW-4R $\rightarrow$ TBG4, TRW-4R $\rightarrow$ TNX3D)

- Approximate field time needed for deployment: 30 days 


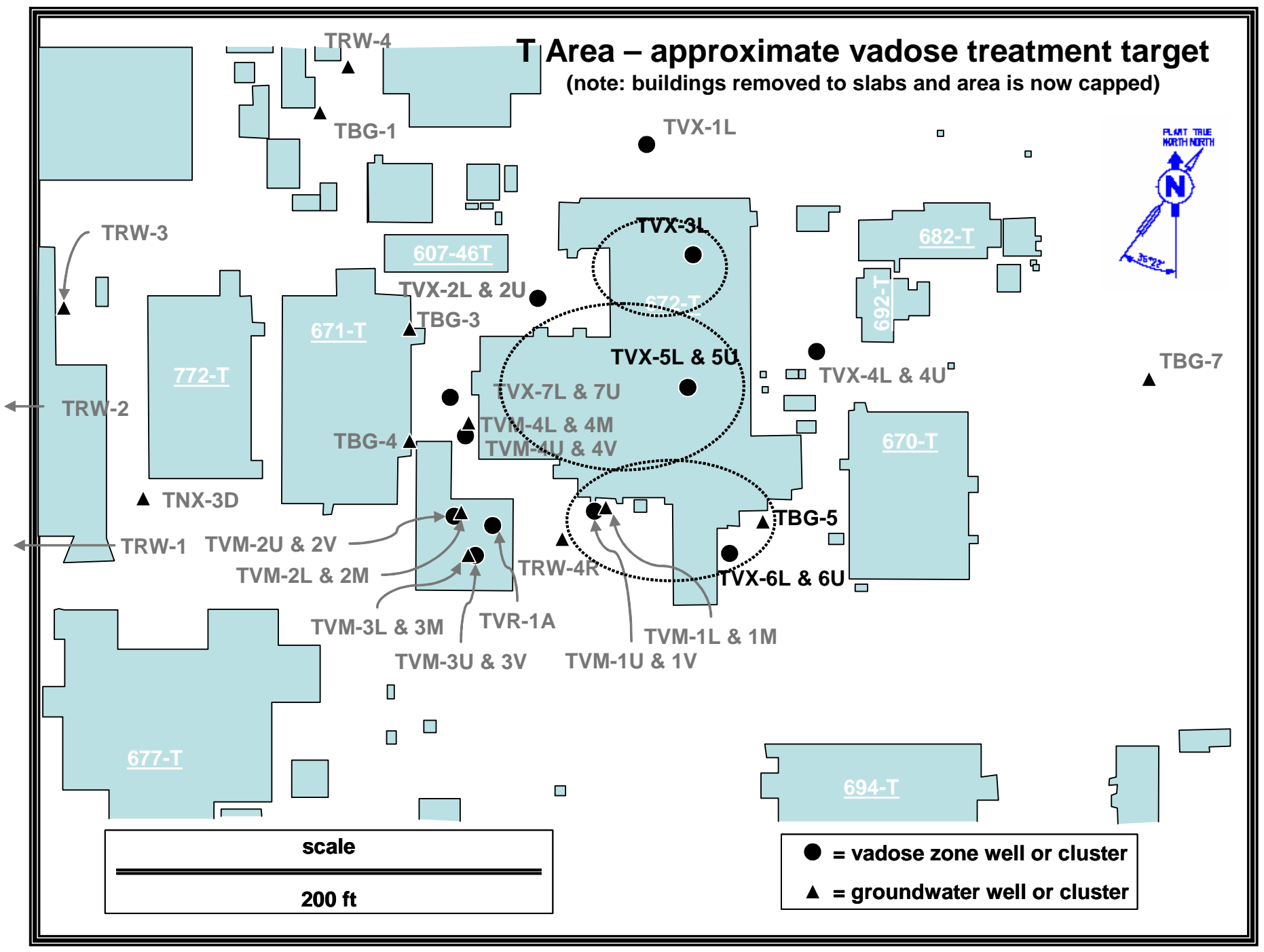

Figure 11 - T Area Source Zone Detail Area - Neat Oil Treatment Target 


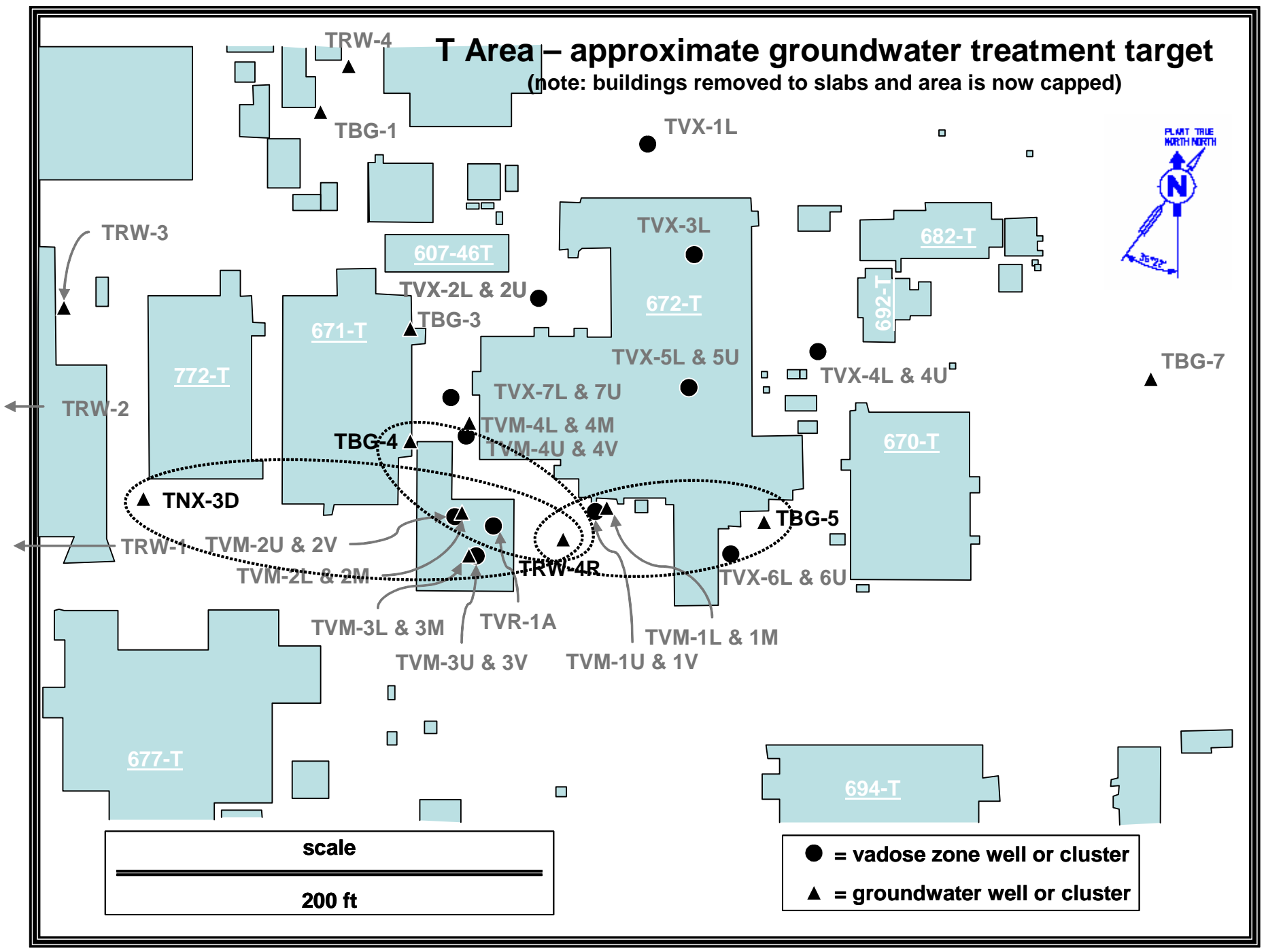

Figure 12 - T Area Source Zone Detail Area - Emulsified Oil Groundwater Treatment Target 


\section{Issues, Uncertainties and Path Forward}

While electron donor addition in general, and emulsified oil deployment in particular are gaining increased acceptance as a practical biodegradation enhancement methods for cVOCs, the technology is still somewhat immature. Thus, we recommend that this effort, if undertaken, be performed as an applied research and development project and that specific issues and uncertainties be addressed through preliminary study and careful monitoring. In particular, the presence and robustness of the microbial community (are appropriate microorganisms present?) requires additional sampling and field monitoring. The preliminary design is based on simple engineering constructs developed for the Air Force Center for Environmental Excellence (AFCEE), but there is currently limited field experience - the AFCEE design guidance manual based on these concepts is still in peer review. Thus, we recommend using the baseline design as described but monitor performance using low cost methods with the idea that additional oil and/or microbial inoculants could be added later (i.e., to address areas that require additional carbon or that were not well treated due to heterogeneity or limited access). This approach provides a viable path to MNA and no further action for cVOCs at T Area. 


\section{References}

Arp, D. J., C. M. Yeager and M. R. Hyman (2001). "Molecular and cellular fundamentals of aerobic cometabolism of trichloroethylene." Biodegradation 12: 81-103.

Birk, G., R. C. Borden and A. Borden (2006). "Short Course: Enhanced Anaerobic Bioremediation Using Edible Oils." Fifth International Conference on Remediation of Chlorinated and Recalcitrant Compounds. Monterey, CA. May 22, 2006.

Borden, R. C. (2000). Natural bioattenuation of anaerobic hydrocarbons and chlorinated solvents in groundwater. Groundwater Contamination by Organic Pollutants: Analysis and Remediation, American Society of Civil Engineers.

Coulibaly, K. M. and R. C. Borden (2003). "Distribution of Edible Oil Emulsions and Permeability Loss in Sandy Sediments." Seventh International Symposium on In situ and On Site Bioremediation. Orlando, FL.

Coulibaly, K. M. and R. C. Borden (2004). "Impact of edible oil injection on permeability of aquifer sands." Journal of Contaminant Hydrology 71: 219-237.

DOD. 2004. Principles and Practices of Enhanced Anaerobic Bioremediation of Chlorinated Solvents. U. S. Department of Defense, Air Force Center for Environmental Excellence. San Antonio, TX.

Freeborn, R. A., K. A. West, V. K. Bhupathiraju, S. Chauhan, B. G. Rahm, R. E. Richardson and L. A. Cohen (2005). "Phylogenetic Analysis of TCEDechlorinating Consortia Enriched on a Variety of Electron Donors." Environmental Science and Technology 39(21): 8358-8368.

Hunter, W. J. (2005). "Injection of innocuous oils to create reactive barriers for bioremediation: Laboratory studies." Journal of Contaminant Hydrology 80(1-2): 31.

Jung, Y. and R. C. Borden (2003). "Subsurface Transport of Emulsified Edible Oil: 3D Sandbox Studies." Seventh International Symposium on In situ and On Site Bioremediation. Orlando, FL.

Kovacich, M. S., D. R. Beck, P. Rich, M. Zack and M. Cannaert (2006). "Direct-Push Injection and Circulation Biobarrier to Remediate a TCE Groundwater Plume." Fifth International Conference on Remediation of Chlorinated and Recalcitrant Compounds. Monterey, CA. May 22, 2006.

Lee, M. D. 2004. TCE plume management through edible oil injection and natural attenuation. Terra Systems Inc. 
Lee, M. D., R. J. Buchanan and D. E. Ellis (2000). "Laboratory studies using edible oils to support reductive dechlorination". Bioremediation and Phytoremediation of Chlorinated and Recalcitrant Compounds, Battelle Press.

Major, D. W., McMaster, M.L., Cox, E.E., Edwards, E.A., Dworatzek, S.M., Hendrickson, E.R., Starr, M.G., Payne, J.A., and Buonamici, L.W. (2002). "Field Demonstration of Successful Bioaugmentation to Achieve Dechlorination of Tetrachloroethene To Ethene." Environmental Science and Technology 36(23): 5106-5116.

McCarty, P. L. (2002). Strategies for insitu bioremediation of chlorinated solvent contaminated groundwater. Groundwater Quality: Natural and enhanced restoration of groundwater pollution. S. F. Thornton and S. E. Oswald, International Association of Hydrological Sciences. 275.

Pfeiffer, P. R., A. R. Bielefeldt, T. Illangasekare and B. Henry (2005). "Partitioning of Dissolved Chlorinated Ethenes into Vegetable Oil." Water Research 39: 45214527.

Sawyer, C. N., P. L. McCarty and G. F. Parkin (1994). Chemistry for Environmental Engineering. New York, McGraw-Hill Inc.

Sutherson, S. S. (2002). Natural and Enhanced Remediation Systems. New York, CRC Press LLC. 